\title{
DESCARTE DO CONHECIMENTO COMO ESTRATÉGIA DE INOVAÇÃO: UM ESTUDO EM UMA INSTITUIÇÃO PÚBLICA DE EDUCAÇÃO NÃO-FORMAL DO NORDESTE DO BRASIL
}

\author{
L.M. P. BRITO' e A. B. C. DE CASTRO 2 \\ ${ }^{1}$ Professora titular do Mestrado em Administração da Universidade Potiguar - UNP, RN. \\ ${ }^{2}$ Administrador no Instituto Federal de Educação, Ciência e Tecnologia do Rio Grande do Norte - IFRN. \\ lydiampbrito@yahoo.com.br ${ }^{1}$; brunnicastro@hotmail.com²
}

Artigo submetido em janeiro/2013 e aceito em fevereiro/2014

DOI: 10.15628/holos.2014.1214

\section{RESUMO}

O descarte do conhecimento é uma atividade complexa, pois o conhecimento passou a ser reconhecido como o principal recurso das organizações, nesse sentido, as organizações passaram a absorver uma panaceia de conhecimentos e o problema agora são os obstáculos psicológicos, políticos e de mensuração que devem ser superados, para que se desfaçam do conhecimento que não satisfaz mais os seus objetivos estratégicos. Diante disso, a questão de pesquisa é: como uma instituição pública de educação não-formal do nordeste do Brasil percebe o descarte do conhecimento organizacional? A pesquisa se justifica pela possibilidade de levantar medidas quantitativas sobre como a organização descarta o conhecimento que pode abrir espaço para inovação, e pela ausência de trabalhos diretamente relacionados nas bases acadêmicas de conhecimento na internet. O objetivo é verificar a partir da percepção dos gestores de uma instituição pública de educação não-formal do nordeste do Brasil como é descartado o conhecimento. Para isso, se utilizou a Seção Descarte do Diagnóstico de Gestão do Conhecimento proposto por Bukowitz e Williams (2002). Foi realizado um estudo de caso e de campo, de abordagem quantitativo-descritiva. Os dados foram tratados em planilhas eletrônicas. Os resultados sinalizam contradições, pois a organização que precisa disseminar saberes de ponta para produtores rurais, não consegue descartar conscientemente o conhecimento datado que possui e que não agrega mais valor. Além disso, a preocupação da organização está em adquirir conhecimento, mesmo que este não esteja alinhado à sua estratégia, e manter seus dados intactos; apesar de não se esforçar para evitar que as pessoas que filtram, direcionam e atualizam os dados permaneçam na organização, nem viabiliza tecnologias e idéias para produzir inovação a partir do conhecimento que adquiri.

PALAVRAS-CHAVE: Descarte Do Conhecimento, Inovação, Gestão Do Conhecimento, Educação Não-Formal

\section{DISPOSAL OF KNOWLEDGE AS A STRATEGY FOR INNOVATION: A STUDY IN A PUBLIC INSTITUTION OF NON-FORMAL EDUCATION NORTHEASTERN BRAZIL ABSTRACT}

\begin{abstract}
Disposal of knowledge is a complex activity because knowledge has become recognized as the main resource of organizations, in this sense, organizations began to absorb a panacea of knowledge and the problem now is the psychological, political and measurement obstacles that must be overcome, so to discard the knowledge that no longer meets its strategic objectives. Therefore, the research question is: as a non -public institution of formal education in northeastern Brazil perceives the disposal of organizational knowledge? The research is justified by the possibility of lifting quantitative measures about the organization drops the knowledge that can make room for innovation, and the lack of jobs directly related to the academic knowledge bases on the internet. The goal is to verify the perception of managers in a non-public institution
\end{abstract}

of formal education in northeastern Brazil is discarded as knowledge. For this, we used the Disposal Section of Diagnostic Knowledge Management and Bukowitz proposed by Williams (2002). A study of case and field, the quantitative-descriptive approach was performed. The data were processed in spreadsheets. The results indicate contradictions, as the organization that needs to disseminate knowledge edge to farmers, unable to consciously discard the knowledge that has dated and not more value. Moreover, the concern of the organization is to acquire knowledge, even if it is not aligned with its strategy, and keep your data intact, despite not strive to prevent people filtering, direct and update the data remain in the organization, nor feasible technologies and ideas to produce innovation from the knowledge I gained.

KEYWORDS: Disposal of Knowledge, Innovation, Knowledge Management, Non-Formal Education. 


\section{INTRODUÇÃO}

Ao longo das três últimas décadas as organizações têm empreendido várias estratégias ou modelos de gestão com o intuito de gerir um recurso ainda não reconhecido como seu principal ativo: o conhecimento organizacional.

A partir desse reconhecimento, que ocorreu principalmente com o processo da mundialização do capital fomentado pelo advento das tecnologias da informação e da comunicação, principalmente da internet, o conhecimento passou a ser reconhecido como o principal recurso das organizações, já que está presente em todas as dimensões da vida organizacional.

Gerir o conhecimento pode provocar mudanças / inovação contínua, portanto, mapeá-lo, sistematizá-lo, socializa-lo e incorporá-lo a produtos e serviços e na tomada de decisão continuamente, através das tecnologias, pessoas e processos, passou a ser uma demanda estratégica fundamental para manter as organizações no mercado, expandir sua ação e garantir seu lugar no futuro.

No entanto, com o objetivo de manter de forma imediata seus padrões de lucro, algumas organizações sejam públicas ou privadas, ainda não internalizaram que a Gestão do Conhecimento é um processo que vai do mapeamento, aquisição, disseminação do conhecimento necessário à sua missão, negócio e estratégias, até o descarte do conhecimento não mais necessário. Assim, passaram a apenas absorver uma panaceia de conhecimentos. O problema agora são os obstáculos psicológicos, políticos e de mensuração que devem ser superados, para que as organizações se desfaçam do conhecimento que não satisfaz mais os seus objetivos estratégicos.

O descarte do conhecimento é uma atividade complexa, pois envolve desde aspectos estratégicos (decisão de gerir o conhecimento); operacionais (transformar o conhecimento tácito em explícito, realizar análises e decidir pelo descarte ou não); e humanos, pois para as pessoas o trabalho realizado tem significados profundos, relacionados à estória dos indivíduos e a cultura organizacional, tornando-se necessário, portanto, para descartar determinado conhecimento ou informação, buscar significados importantes nas novas atividades a serem realizadas, de forma que as pessoas sintam que estão ganhando com a mudança.

Isto significa atualizar e buscar mudanças substantivas e qualitativas dos conhecimentos relacionados à área fim da competência essencial da organização, ou seja, quando a organização descarta o conhecimento que não contribui para inovação ou para mantê-la competitiva, abre espaço e tempo para incorporar o conhecimento realmente relevante, que no caso da instituição pesquisada, envolve conhecimentos das áreas de: engenharia agronômica, florestal e de pesca; veterinária; zootecnia; administração; psicologia; pedagogia; nutrição; serviço social e sociologia, justificando-se a pesquisa do ponto de vista institucional. Saberes estes, que estão em evolução e aperfeiçoamento contínuo e que são fundamentais para beneficiar agricultores familiares e promover o desenvolvimento regional, semelhante à missão da organização pesquisada.

Diante disso, a questão principal de pesquisa é: como uma instituição pública de educação não-formal do Nordeste do Brasil percebe o descarte do conhecimento organizacional? 
A pesquisa se justifica ainda, pela possibilidade de levantar onde estão as lacunas ao descarte do conhecimento, bem como compreender que estratégias de descarte do conhecimento são utilizadas, já que se trata de uma instituição de educação não-formal cujo principal recurso é o conhecimento, bem como, compreender que variáveis concorrem para o descarte do conhecimento como estratégia de inovação. Além disso, o interesse pelo tema surgiu em decorrência de uma pesquisa realizada em portais acadêmicos na internet, em que foram encontradas poucas pesquisas, e entre as encontradas, relacionam-se de forma indireta ao tema Descarte do Conhecimento, como por exemplo, sobre "Esquecimento Organizacional" e "Desaprendizagem Organizacional".

O objetivo geral é: verificar a partir da percepção dos gestores de uma instituição pública de educação não formal do nordeste do Brasil como é descartado o conhecimento. A escolha dos gestores como público alvo se justifica, pois são eles que conhecem o fluxo do conhecimento na organização, bem como utilizam do conhecimento para tomada de decisão e são os gestores que selecionam e filtram o conhecimento que pode ser incorporado nos repositórios, nos produtos e serviços. Para a consecução desta pesquisa, optou-se por um estudo de caso e de campo, de abordagem quantitativo-descritiva.

Além da introdução, o artigo explora no referencial teórico a perspectiva conceitual sobre Gestão do Conhecimento com foco no modelo proposto por Bukowitz e Williams (2002). Em seguida são apresentados os procedimentos metodológicos, a análise dos resultados e as considerações finais.

\section{FUNDAMENTOS TEÓRICOS}

O conhecimento é o único recurso significativo atualmente e assumiu a supremacia, em detrimento do antigo modelo físico (Drucker, 1993; Schlesinger et al 2008; Strauhs et al, 2012), pois "o valor da maioria dos produtos e serviços depende principalmente de como os fatores intangíveis baseados no conhecimento - como know-how tecnológico, projeto do produto, apresentação de marketing, compreensão do cliente, criatividade pessoal e inovação - podem ser desenvolvidos." (NONAKA E TAKEUCHI, 1997, p.5).

Significa dizer que o conhecimento se tornou "o principal ingrediente do que produzimos, fazemos, compramos e vendemos. Resultado: administrá-lo - encontrar e estimular o capital intelectual, armazená-lo, vendê-lo e compartilhá-lo - tornou-se a tarefa econômica mais importante dos indivíduos, das empresas, dos países." (STEWART, 1998, p.11).

O conhecimento é valioso porque está próximo da ação (NONAKA E TAKEUCHI, 1997; SVEIBY, 1998; WANG E NOE, 2011; BASSETTO, 2011). "Um conhecimento melhor pode levar, por exemplo, a eficiência mensurável em desenvolvimento de produtos e na sua produção." (DAVENPORT e PRUSAK, 1998, p.7).

No entanto, segundo Nonaka e Takeuchi (1997); Sveiby (1998); Davenport e Prusak (1998); Lara (2004); Tavares (2010); Strauhs et al. (2012); Brito, Oliveira e Castro (2012), o conhecimento não pode ser descrito por meio de palavras por ser principalmente tácito (fruto de regras, de procedimentos, habilidades de comunicação, experiências adquiridas pela reflexão sobre erros e sucessos / insucessos do passado, crenças e compromissos, julgamentos de valor, adquirido nas 
redes sociais, encontros informais, bate-papos, fóruns etc.), e sempre sabemos mais do que podemos expressar.

O desafio para as organizações, nesse cenário, é desenvolver práticas de gestão do conhecimento.

\subsection{GESTÃO DO CONHECIMENTO (GC)}

A GC passou a ser prioridade máxima em função da urgência e da necessidade premente de diferenciação no mercado através do conhecimento, sendo essa a fonte clara de competitividade duradoura, impulsionada pela rápida evolução das tecnologias de informação e comunicação. (WILLIAMS E BUKOWITZ, 2002; SILVA ET AL, 2009; DIHL, 2010; STRAUHS ET AL., 2012).

Trata-se de uma estratégia de obter, utilizar, contribuir, avaliar, construir, manter e descartar um recurso intangível - o conhecimento, cuja propriedade deixa de ser de alguns poucos privilegiados na organização, como os gestores em geral ou mesmo os funcionários especializados, para se tornar uma ferramenta de gestão organizacional compartilhada com todos os profissionais da organização, em todos os níveis, seja operacional, tático ou estratégico. (NONAKA E TAKEUCHI, 1997; STEWART, 1998; DAVENPORT E PRUSAK, 1998; BUKOWITZ E WILLIAMS, 2002; LARA, 2004; TERRA, 2005; STRAUHS ET AL., 2012). Pois, promove a criação de vantagem competitiva, vinculada à capacidade das organizações de se reinventarem continuamente e de desenvolverem suas competências essenciais, produtos e serviços inovadores. (COSTA ET AL, 2009). Foi o que aconteceu com as organizações japonesas na década de noventa.

A GC nas organizações públicas segue o mesmo contexto, a diferença é que nas organizações privadas as estratégias de GC são adotas por que talvez se não inovarem tendem a desaparecer com uma maior rapidez; as entidades públicas são motivadas a buscar esse novo cenário para lidar com as pressões legítimas de uma sociedade cada vez mais exigente. (SCHLESINGER ET AL, 2008; TRIGUEIRO E MARQUES, 2012; BATISTA, 2012).

Nesse contexto, vários autores têm contribuído para construção de modelos de GC. O Quadro 1 resume alguns dos principais modelos com as contribuições dos autores.

QUADRO 1 - Modelos de Gestão do Conhecimento e seus componentes. Fonte: Adaptado de Leite e Costa (2007); Schlesinger et al (2008); Brito, Castro e Oliveira (2012); Strauhs et al (2012); Batista (2012).

\begin{tabular}{c|c|lcl} 
Autor do Modelo & Ano & \multicolumn{1}{c}{ Foco do Modelo } \\
\hline Nonaka e Takeuchi & 1997 & $\begin{array}{l}\text { O processo de criação do conhecimento organizacional pela conversão do } \\
\text { conhecimento tácito em explicito a partir de quatro etapas, sendo: Socialização, } \\
\text { Externalização, Combinação e Internalização, do Espiral de Criação do } \\
\text { Conhecimento e a incorporação desse conhecimento no desenvolvimento de } \\
\text { produtos, serviços e na tomada de decisão. }\end{array}$ \\
\hline Davenport e Prusak & 1998 & $\begin{array}{l}\text { Classificação dos conhecimentos: Mercado do Conhecimento (visa rastrear o local } \\
\text { onde se encontra o conhecimento); Geração do Conhecimento (trata da interação } \\
\text { no ambiente de trabalho para viabilizar a partilha de informações e sua } \\
\text { incorporação às experiências, valores, normas etc.); Codificação do Conhecimento } \\
\text { (trata da acessibilidade às diversas modalidades de conhecimento na organização); } \\
\text { e, Compartilhamento do Conhecimento (proporcionar ambiência para trocar ideias } \\
\text { e socialização do conhecimento tácito). }\end{array}$ \\
\hline Leonar-Barton & 1998 & $\begin{array}{l}\text { Laboratório de Aprendizagem: trata da criação de ambiente nas organizações para } \\
\text { aprendizagem e utilização do conhecimento das pessoas e sua incorporação nas } \\
\text { práticas e valores organizacionais através dos gerentes e do que chamou de }\end{array}$ \\
\hline
\end{tabular}




\begin{tabular}{|c|c|c|}
\hline & & $\begin{array}{l}\text { subsistemas: Resolução de problemas nas atividades correntes, Integração do } \\
\text { conhecimento no interior da empresa por meio de funções e projetos, Inovação e } \\
\text { experimentos visando ao longo prazo, e Unificação das entradas dos } \\
\text { conhecimentos externos. }\end{array}$ \\
\hline Sveiby & 1998 & $\begin{array}{l}\text { Tem por base o ativo intangível da organização, ou seja, diz respeito à capacidade } \\
\text { de competitividade, às competências dos colaboradores e à imagem da } \\
\text { organização percebida pelos clientes, a partir dos seguintes componentes: } \\
\text { Competência dos Funcionários, Estrutura Interna e Estrutura Externa. }\end{array}$ \\
\hline Stewart & 1998 & $\begin{array}{l}\text { Aquisição, desenvolvimento e remodelação de capital intelectual. Como descobrir, } \\
\text { gerenciar e desenvolver o capital intelectual por meio da simulação. }\end{array}$ \\
\hline $\begin{array}{l}\text { Von Krogh, Ichijo e } \\
\text { Nonaka }\end{array}$ & 2001 & $\begin{array}{l}\text { Proporcionar uma atmosfera para o aprendizado e disseminação de informações } \\
\text { através de condições capacitadoras. Recursos humanos, motivação de } \\
\text { funcionários, treinamentos, qualidade, trabalho em equipe, brainstorming, entre } \\
\text { outras estratégias. }\end{array}$ \\
\hline Bukowitz e Williams & 2002 & $\begin{array}{l}\text { Estruturação dos processos de GC com base no DGC (Diagnóstica de Gestão do } \\
\text { Conhecimento), que se divide em dois processos: Tático (seções - obtenha; utilize; } \\
\text { aprenda; contribua), e processo Estratégico (seções - avalie; construa/ mantenha } \\
\text { e descarte). }\end{array}$ \\
\hline Choo & 2003 & $\begin{array}{l}\text { Como as organizações usam a informação para criar significado, construir } \\
\text { conhecimento e tomar decisões. Mudança ecológica, interpretação, seleção e } \\
\text { retenção. }\end{array}$ \\
\hline Terra & 2005 & $\begin{array}{l}\text { Avaliação da GC considerando-se as dimensões da prática gerencial. Elementos } \\
\text { construtivos: metas de conhecimento, identificação, desenvolvimento, } \\
\text { compartilhamento e distribuição, utilização, preservação e avaliação do } \\
\text { conhecimento. }\end{array}$ \\
\hline Leite e Costa & 2007 & $\begin{array}{l}\text { Os processos de comunicação científica: Identificação/mapeamento, Aquisição, } \\
\text { Armazenagem/organização, Compartilhamento e Criação. }\end{array}$ \\
\hline Schlesinger et al & 2008 & $\begin{array}{l}\text { Propiciar às organizações públicas um caminho para a compreensão, análise, } \\
\text { identificação e implementação do processo de criação e troca de conhecimento, } \\
\text { com fundamento em três pilares, sendo: bases teóricas sobre a criação e } \\
\text { compartilhamento do conhecimento, elementos sobre a aprendizagem em } \\
\text { comunidades de práticas e identificação de estilos cognitivos. }\end{array}$ \\
\hline Batista & 2012 & $\begin{array}{l}\text { Trata-se de um modelo híbrido, sendo descritivo, pois descreve os elementos } \\
\text { essenciais da GC (Visão, Missão, Objetivos Estratégicos, Estratégias e Metas); e } \\
\text { prescritivo, pois orienta como implementar a GC através de um Manual de } \\
\text { Implementação para a Administração Pública, que apresenta como elementos } \\
\text { viabilizadores: Liderança, Tecnologia, Pessoas e Processos; como elementos do } \\
\text { processo de GC: Identificar, Criar, Compartilhar e Aplicar; e, como partes } \\
\text { interessadas: cidadão - Usuário e Sociedade. }\end{array}$ \\
\hline
\end{tabular}

Diante desses modelos, considerando-se o objetivo da pesquisa, optou-se pela abordagem das autoras Bukowitz e Williams (2002) que propõem a estruturação dos processos de GC com base em um Diagnóstico de Gestão do Conhecimento (DGC), que no caso deste estudo se deteve na Seção Descarte do referido diagnóstico.

O DGC é um modelo que provoca o pensamento sobre os elementos que possam envolver e serem combinados para criar uma abordagem exitosa da GC nas organizações, a partir das mudanças desencadeadas pelo micro e macro ambiente. Além disso, o modelo possibilita a criação de uma medida de base que pode ser utilizada para rastrear o desempenho das organizações e dá a possibilidade de mapear os caminhos que já foram percorridos pelas organizações e que produziram benefícios através do conhecimento.

A "Seção Descarte", também referenciada como "Seção Despoje" no modelo de Bukowitz e Williams (2002), enquadra-se no processo Estratégico da Gestão do Conhecimento, conforme a 
Figura 1, pois visa avaliar continuamente o capital intelectual existente na organização em comparação com as necessidades futuras, com vistas a manutenção competitiva da organização no mercado. O objetivo dessa seção é verificar como a organização "rejeita" o conhecimento que não tem utilidade para mantê-la viável no mercado.

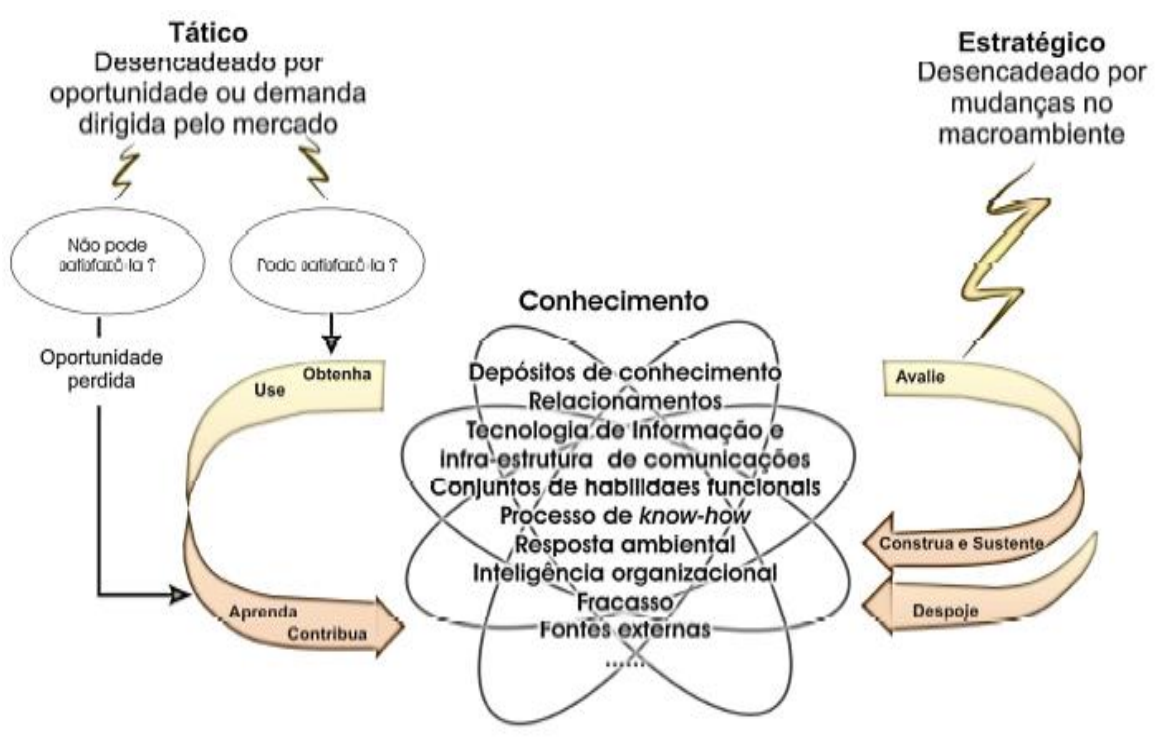

FIGURA 1 - Estruturação do processo de Gestão do Conhecimento. Fonte: Adaptado de Bukowitz e Williams (2002)

\subsubsection{Contexto}

"Assim como a maioria das pessoas tende a acumular, as organizações também acham difícil abandonar as atividades e os recursos que outrora produziram resultados valiosos." (BUKOWITZ E WILLIAMS, 2002, p. 337), já que os indivíduos e os grupos estão altamente envolvidos na gestão desses recursos e atividades, assim, os problemas políticos envolvidos em realocá-los para fora da organização, são espinhosos para se negociar.

A palavra descarte está ligada a "rejeitar". Aqui está vinculada especificamente a palavrachave que tem relação com o verbo "descartar". Considerando-se que o termo descarte foi pouco encontrado dentro da visão organizacional desejada, utilizou-se o Dicionário Aurélio (2010) que traz o termo "descartar" com o significado de rejeitar após o uso.

Entre as poucas pesquisas encontradas, indiretamente relacionadas com o tema, Remor et al (2010) colocam o descarte do conhecimento como uma atividade de "esquecimento organizacional", e citam que isso é necessário para dar lugar aos conhecimentos novos, para evitar que conhecimentos incompatíveis entre si e com a organização sejam incorporados na memória, e para a formação de uma memória seletivamente útil e dirigida para os objetivos da organização.

Barreto (2007) acrescenta, em seu estudo, a discussão entre a relação da memória, estoque de conhecimento e esquecimento quando coloca que: certamente não podemos treinar o esquecimento como treinamos para aumentar ou aprimorar nossa memória. O esquecimento é uma qualidade da memória, que a preserva e a mantém saudável. Nossa memória funciona, e só funciona porque nos é dada a capacidade de esquecimento. 
Para Bukowitz e Williams (2002) o descarte do conhecimento é a fase de despojamento do conhecimento que não gera mais valor para a organização e se acumula nas bases do conhecimento / repositórios dificultando a seleção daquele que realmente gera vantagem competitiva e inovação.

Portanto, o descarte do conhecimento é uma qualidade, baseada nos aspectos estratégicos (missão, visão, valores, objetivos, metas, estratégias organizacionais, políticas etc.), operacionais (tecnologias da informação e estruturas organizacionais) e humanos, de selecionar na memória (repositórios) o conhecimento que não agrega valor para a organização e que dificulta a extração do conhecimento que pode gerar inovação. A atividade de descarte requer aprendizagem, em virtude dos obstáculos psicológicos, políticos e de mensuração que devem ser superados, para que as organizações se desfaçam do conhecimento conscientemente.

Para Choo (2003), é uma forma de empenhar-se na aprendizagem constante, o que inclui desaprender / esquecer pressupostos, normas e crenças que perderam validade; mobilizar o conhecimento e a experiência de seus membros para gerar inovação e criatividade; focalizar seu conhecimento em ações racionais e decisivas.

Porém, poucas organizações parecem empreender esse passo da GC com uma visão clara, ou um processo estabelecido que propicie a atualização, ou o alinhamento do conhecimento com a estratégia do negócio de modo que possa favorecer a inovação contínua. (SCHLESINGER ET AL, 2008; COSTA ET AL, 2009; SILVA ET AL, 2009; TAKAHASHI E FISCHER, 2009; DIHL ET AL, 2010; BRITO, OLIVEIRA E CASTRO, 2012; STRAUHS, 2012; WOSZEZENKI ET AL, 2012).

Igarashi et al (2008); Fernandez e Sune (2009); Silva et al. (2009) ratificam, quando colocam que, a investigação científica sobre a Gestão do Conhecimento no Brasil tem se concentrado nos processos táticos de criação de conhecimento, uso e transferência; dedicando-se pouca atenção aos estudo de descarte, e isso tem causado um crescimento científico heterogêneo sobre a temática.

Entretanto, segundo Bukowitz e Williams (2002); Fernandez e Sune (2009); Wang e Noe (2011); Hou (2012), em uma visão mais internacionalizada, colocam que algumas organizações estão começando a desenvolver práticas de descarte da sua propriedade intelectual, com o objetivo de evitar que as organizações o façam inconscientemente, jogando-o - o conhecimento fora como se jogava os ativos tangíveis, muitas vezes com uma sensação desfavorável de que estão se despojando de mais do que podem se dar conta.

É o velho princípio de só dar valor ao que foi perdido ou quando as organizações deixam de ganhar/lucrar. Bukowitz e Williams (2002) colocam como exemplo alguns gerentes de nível médio que atuavam entre a linha de frente e os executivos, considerados "sacrificáveis", revelaram-se na sua ausência vitais avaliadores do conhecimento. Como foi no caso do legado da reengenharia e do enxugamento que "resultou em uma drenagem cerebral séria para muitas organizações, [...] sendo duas formas básicas: 1- pessoas experientes vão embora por iniciativa própria; 2- pessoas experientes são criticadas como parte de uma iniciativa de enxugamento indiscriminada." (p. 21).

As organizações não percebiam que o papel dos gerentes intermediários, nesse caso, era filtrar e dar sentido ou transformar a informação coletada na linha de frente em soluções para os problemas do dia-a-dia das organizações. E, "depois de cometer dispendiosos erros por ignorar a 
importância do conhecimento, muitas empresas estão agora lutando para entender melhor o que sabem, o que precisam saber e o que fazer a esse respeito." (DAVENPORT E PRUSAK, 1998, p X).

Entre as principais práticas de descarte do conhecimento as autoras Bukowitz e Williams (2002) destacam: vender, licenciar e doar uma patente; descartar ou vender um negócio nãoalinhado (desfocado da competência essencial da organização); terceirizar um processo funcional ou operacional; retreinar, remanejar ou demitir indivíduos com habilidade obsoletas ou inadequadas; substituir ou requalificar os sistemas de Tecnologias da Informação e determinar parcerias, alianças e contratos.

Segundo Remor et al (2010) o descarte do conhecimento também pode ocorrer de forma proposital através do que chamou de "esquecimento proposital", que acontece quando algum tipo de conhecimento é propositalmente removido da memória organizacional.

O descarte do conhecimento também trata da disciplina que as organizações devem ter em não absorver, de não ir em uma direção somente porque todos estão indo, ou seja, ceder à resposta submissa de acrescentar uma especialização porque a concorrência está indo naquela direção. (BUKOWITZ E WILLIAMS, 2002; COSTA ET AL, 2009; SILVA ET AL, 2009; DIHL, 2010).

Isso força as organizações a conceberem maneiras novas e criativas de perseguirem seus objetivos estratégicos ao ter que criar novos conhecimentos para manter-se na sua competência essencial. Segundo Bukowitz e Williams (2002, p. 344) "Isso pode ser realizado pela perseguição de estratégias de não-absorção, como trabalhar com o que você já tem ou tomar emprestado o material alheio", pois despojar-se do conhecimento que não seja importante libera tempo e recursos para aumentar e manter aquele que é importante estrategicamente para gerar a inovação, que poderá diferenciar a organização frente ao mercado.

Nonaka e Takeuchi (1997) colocaram que Drucker, na década de 80, já havia levantado a importância das organizações estarem preparadas para abandonar o conhecimento que se tornou obsoleto e se preparar para o novo através dos seguintes pontos: (1) melhoria contínua de todas as atividades já existentes; (2) desenvolvimento de novas aplicações a partir de seus próprios sucessos; e (3) inovação contínua como um processo organizado.

A consolidação desta pesquisa pode ser melhor compreendida por meio dos procedimentos metodológicos e da análise dos resultados que se seguem.

\section{METODOLOGIA DA PESQUISA}

A pesquisa quanto à forma de abordagem do problema foi classificada como quantitativa (GIL, 2006; MARCONI, 2008; LAKATOS, 2008), pois torna possível a análise da Seção Descarte do DGC que envolve método quantitativo / estatístico para a avaliação das variáveis que buscam as respostas do problema de pesquisa. Quanto aos procedimentos técnicos, conforme Gil (2006); Vergara (2007); Acevedo e Nohara (2006); Yin (2010), a pesquisa se classifica como estudo de caso e como pesquisa de campo. Foi utilizado o método descritivo, que conforme Gil (2006); Acevedo e Nohara (2006); Vergara (2007); Yin (2010), viabiliza a descrição de uma determinada população e suas características.

A população compreendeu $90 \%$ dos 40 gestores envolvidos nos níveis tático e estratégico em atividade durante os meses de fevereiro a abril do ano de 2012. 
A estratégia utilizada para a aplicação e coleta do instrumento de pesquisa foi o envio através de endereço eletrônico e entrega nos setores de atuação dos gestores respondentes. 0 instrumento utilizado para a coleta de dados foi o questionário desenvolvido e validado por Bukowitz e Williams (2002), sendo utilizada apenas a Seção Descarte do modelo, que é composta por 20 (vinte) questões fechadas. Também foi utilizado um questionário de levantamento de dados sócio-demográficos acrescido de duas questões, sendo respectivamente, uma fechada e uma aberta, sendo: Você já ouviu falar em Gestão do Conhecimento? E, Você conhece práticas de Gestão do Conhecimento na instituição que trabalha?

Quanto ao questionário das autoras Bukowitz e Williams (2002) tem-se que, para cada pergunta, as autoras adotaram uma escala de intensidade gradativa crescente de 1 a 3 pontos com variação de fraco $(\mathrm{Fr})$ a forte $(\mathrm{Fs})$, sendo quanto maior o percentual obtido, melhor o desempenho. Os itens do questionário foram tabulados através de planilhas eletrônicas, obtendo-se os cruzamentos entre as variáveis de interesse para análise, que são apresentadas através de gráficos e tabelas com a frequência das respostas em média percentual.

Bukowitz e Williams (2002) adotam como parâmetro, encontrado em suas pesquisas, o percentual de gestão do conhecimento médio entre 30 a $70 \%$ para cada seção do DGC, inclusive para a Seção Descarte.

Para aprofundamento da análise da Seção Descarte do DGC, foram utilizados os indicadores de Gestão do Conhecimento associados às questões do instrumento de pesquisa propostos por Brito, Oliveira e Castro (2012), conforme Quadro abaixo.

QUADRO 2: Constructos da Seção Descarte. Fonte: Adaptado de Silva et al., (2009); Brito, Oliveira e Castro (2012).

\begin{tabular}{|c|c|c|}
\hline Indicador de GC & Conceituação & Questão \\
\hline $\begin{array}{ll}\text { Avaliação do } \\
\text { conhecimento }\end{array}$ & $\begin{array}{l}\text { Avaliar se o conhecimento construído pode ser utilizado de outras } \\
\text { maneiras ou descartado com os componentes que contem. }\end{array}$ & $5,13,16$ \\
\hline $\begin{array}{l}\text { Processos de gestão } \\
\text { do conhecimento / } \\
\text { Contextualização / } \\
\text { Política de Gestão do } \\
\text { conhecimento }\end{array}$ & $\begin{array}{l}\text { Verificar se a organização tenta perseguir atividades de valor mais alto } \\
\text { ou alocar as pessoas nas habilidades e expertises certas antes de pensar } \\
\text { em demiti-las e se tem a capacidade de se re-instrumentar antes de } \\
\text { empregar novas habilidades com um novo grupo de trabalhadores do } \\
\text { conhecimento, analisando-se o impacto da perda pessoas com } \\
\text { conhecimento estratégico importante. }\end{array}$ & $\begin{array}{l}2,7 \\
10,13,16,17 \\
20\end{array}$ \\
\hline $\begin{array}{l}\text { Papéis de gestão do } \\
\text { conhecimento }\end{array}$ & $\begin{array}{l}\text { Avaliar se existe participação das pessoas da organização em grupos de } \\
\text { pesquisa sobre o ramo de negócio da organização ajudando a decidir a } \\
\text { necessidade de aquisição do conhecimento. }\end{array}$ & 6 \\
\hline Parceria & $\begin{array}{l}\text { Verificar se há a construção de alianças com outras organizações com a } \\
\text { inclusão de pessoal como aprendizes para determinar a necessidade de } \\
\text { aquisição de novos conhecimentos ou expertises para manter nossa base } \\
\text { de conhecimento atualizada. }\end{array}$ & $11,12,19$ \\
\hline Processo decisório & $\begin{array}{l}\text { Avaliar se a organização reflete sobre o quanto podemos alavancar o } \\
\text { conhecimento adquirido, sobre o descarte planejado do conhecimento, } \\
\text { recusar trabalhos se não construir conhecimento que agregue à } \\
\text { organização e sobre terceirizar habilidades que não sustentam a } \\
\text { competência essencial da organização. }\end{array}$ & $\begin{array}{l}1,3,8,13,14 \\
15\end{array}$ \\
\hline $\begin{array}{l}\text { Reconhecimento e } \\
\text { valorização da gestão } \\
\text { do conhecimento }\end{array}$ & $\begin{array}{l}\text { Verificar se há reconhecimento pela organização do impacto sobre a } \\
\text { lealdade, a contribuição e o compromisso quando da partida de pessoas } \\
\text { chaves da organização. }\end{array}$ & 10,20 \\
\hline $\begin{array}{l}\text { Compartilhamento } \\
\text { do conhecimento/ } \\
\text { Comunicação/ } \\
\text { Relacionamento }\end{array}$ & $\begin{array}{l}\text { Avaliar a capacidade de compreender o impacto dos relacionamentos na } \\
\text { produtividade antes da automatização das tarefas e tratar as pessoas } \\
\text { afetadas com dignidade e respeito para manter a nossa base de } \\
\text { conhecimento intacta. }\end{array}$ & $2,4,9,19$ \\
\hline
\end{tabular}




\section{CARACTERIZAÇÃO DA ORGANIZAÇÃO DE EDUCAÇÃO NÃO-FORMAL}

Trata-se de uma organização pública que atua com Assistência Técnica e Extensão Rural (ATER) fundada em 1955 com a proposta de desenvolvimento sócio-econômico do homem do campo, tendo como foco o crédito rural supervisionado e o trabalho cooperativo (envolvendo lideranças, grupos de produtores, atividades com jovens rurais, etc.) baseado em princípios educacionais, na busca do aprendizado na agricultura, pecuária e economia doméstica, na intenção de viabilizar tecnologias voltadas para a melhoria da produção, aumento da produtividade e aproveitamento das riquezas naturais, bem como cuidados com os alimentos, vestuário e administração do lar (EMATER-RN, 2009).

As primeiras atividades de ATER no Nordeste do Brasil, segundo Silva Filho (2005); Sousa et al. (2009), eram vinculadas às ações da Igreja, parceira, principalmente, nas questões de saúde e educação e, também, menciona a natureza política dessas, ao relatar a importância dada aos prefeitos, como forma de desenvolvimento dos municípios.

Atualmente, após vários processos de reestruturação, as instituições de assistência técnica e extensão rural no Nordeste e no Brasil, passaram a atuar com base nos cinco princípios a partir da política nacional de ATER, sendo: (1) acessibilidade do serviço de ATER aos seus beneficiários, (2) promoção do desenvolvimento rural sustentável, (3) abordagem multidisciplinar e interdisciplinar, com ênfase nas metodologias participativas e tecnologias agroecológicas, (4) estabelecimento de um modelo de gestão democrático, (5) processos educativos permanentes e continuados a partir de um enfoque dialético, humanista e construtivista (MDA, 2004). Conforme o último princípio, ou seja, do ponto de vista educativo, o serviço de ATER supõe a quebra da hierarquia de saberes e o respeito aos conhecimentos dos agricultores, em detrimento da prática difusionista, em que o conhecimento era difundido de maneira unilinear e unidirecional do técnico para o agricultor. (CAPORAL, 2009).

Dentro deste contexto, a organização pesquisada, se reveste de importância e tem desafios a serem superados. O primeiro deles se refere ao cumprimento de sua missão: "contribuir para a promoção do agronegócio e favorecer o desenvolvimento de ações geradoras de bem-estar, por meio do serviço de assistência técnica e extensão rural pública", para atingir a sua visão de futuro: "melhor distribuição de renda, estímulo e participação das comunidades rurais, inclusão dos agricultores e seus familiares nas ações que levam ao progresso e desenvolvimento sustentável", por meio de valores, tais como: comprometimento, credibilidade, ética, valorização do saber e da cultura, valorização das pessoas, igualdade de direitos, inclusão social, qualidade de vida e desenvolvimento sustentável. (SOUSA ET AL., 2009).

Como agente impulsionador do desenvolvimento rural sustentável, com vistas a sua missão e visão, a instituição pesquisada conta com uma sede própria, além de dois Centros de Treinamento, 72 Unidades Digitais para capacitação de servidores e beneficiários, 154 Unidades Locais de Apoio ao Produtor Rural que assistem 100\% do território do Estado onde se localiza no Nordeste do Brasil, atende a 105.000 agricultores/as familiares em 2.072 comunidades, e tem um 
quadro com cerca de 528 profissionais nas mais diversas áreas de conhecimento, sendo: engenharias (agronômica, florestal e de pesca); veterinária; zootecnia; agropecuária, administração; psicologia; pedagogia; nutrição; serviço social, turismo rural e sociologia (SOUSA ET AL., 2009).

É uma organização que impulsiona o desenvolvimento regional através do serviço público, gratuito e de qualidade de extensão rural, que é uma alternativa diante das dificuldades de se constituir a educação formal / escolar no campo, por isso, priorizou-se a educação não escolar / não-formal por meio dos profissionais das citadas áreas, chamados de extensionistas rurais, cujo conhecimento e prática, possibilitam dirimir questões do interesse dos agricultores / as e seus familiares.

\section{ANÁLISE DOS DADOS DA PESQUISA}

\subsection{CARACTERIZAÇÃO DOS RESPONDENTES}

A maioria dos gestores respondentes da pesquisa ocupa função de chefia administrativa e de gerência / assessoria de unidade de apoio ao produtor rural, sendo mulheres em sua maior parte, com faixa etária acima de 35 anos, escolaridade igual ou maior ao ensino superior, e apresentam mais de 5 anos na função que executam. A maioria dos respondentes, considerandose apenas entre os que apresentaram escolaridade igual ou maior que o ensino superior, disse ter ouvido falar em Gestão do Conhecimento e conheciam práticas de gestão do conhecimento na instituição que trabalhavam.

\subsection{DGC: SEÇÃO DESCARTE}

Considerando-se a metodologia da pesquisa utilizada, percebeu-se que, conforme a Tabela 1, é baixo o desempenho da Seção Descarte do DGC na instituição pesquisada. Significa dizer que é difícil para a instituição pesquisada abandonar ou descartar / rejeitar / despojar-se do conhecimento que não tem utilidade presente ou futura, mas que ocupa os repositórios, ou mesmo, deixar de adquirir conhecimento que não agregue valor. Apesar do percentual encontrado, este se encontra entre a média aceitável, conforme Bukowitz e Williams (2002).

TABELA 1 - Resultado geral das pontuações e percentuais obtidos por seção

\begin{tabular}{c|c|c}
\hline Seção & Percentual da Seção (\%) & Medida de desempenho \\
\hline Descarte & 33,6 & Baixa intensidade \\
\hline
\end{tabular}

Fonte: dados da pesquisa

Em seguida tem-se a distribuição dos Indicadores de Gestão do Conhecimento, propostos por Brito, Oliveira e Castro (2012), utilizados para o aprofundamento da análise dos dados da Seção Descarte do DGC. 


\subsubsection{Indicadores de Gestão do Conhecimento associados à Seção Descarte}

A partir da metodologia adotada para esta pesquisa, com vista para o Gráfico 1, percebeuse que o indicador "Processos de gestão do conhecimento/ Contextualização/ Política de Gestão do conhecimento" apresentou-se como "fraco", significa dizer que: quando surge uma nova oportunidade, a organização não tenta reinstrumentar suas habilidades existentes antes de empregar um novo grupo / equipe de pessoas em um novo trabalho, deixando-se de perseguir ou de perceber as estratégias de não-absorção. (BUKOWITZ E WILLIAMS, 2002; BRITO, OLIVEIRA E CASTRO, 2012).

Além disso, quando há a possibilidade de dispensar pessoas, a organização não imagina como perseguir atividades de valor mais alto em vez de dispensá-las, não rever suas práticas de valorização de pessoal para se certificar de que não está perdendo pessoas com conhecimento estrategicamente importante, e não leva em conta o impacto que tem o fato de deixar ir embora pessoas com capacidade de acabativa, contribuição, lealdade e compromisso.

Também se pôde perceber que a organização de forma inconsciente descarta ativos tangíveis (documentos, livros, sistemas de informação, anotações etc), sem saber dos componentes de conhecimento que eles contêm. Significa que a organização pode está despojando-se de conhecimento estrategicamente útil e escorregando para a anorexia organizacional, conforme colocam Bukowitz e Williams (2002), pois rotineiramente, a organização não examina se está sustentando o seu conhecimento estratégico às custas de outros conhecimentos considerados importantes.

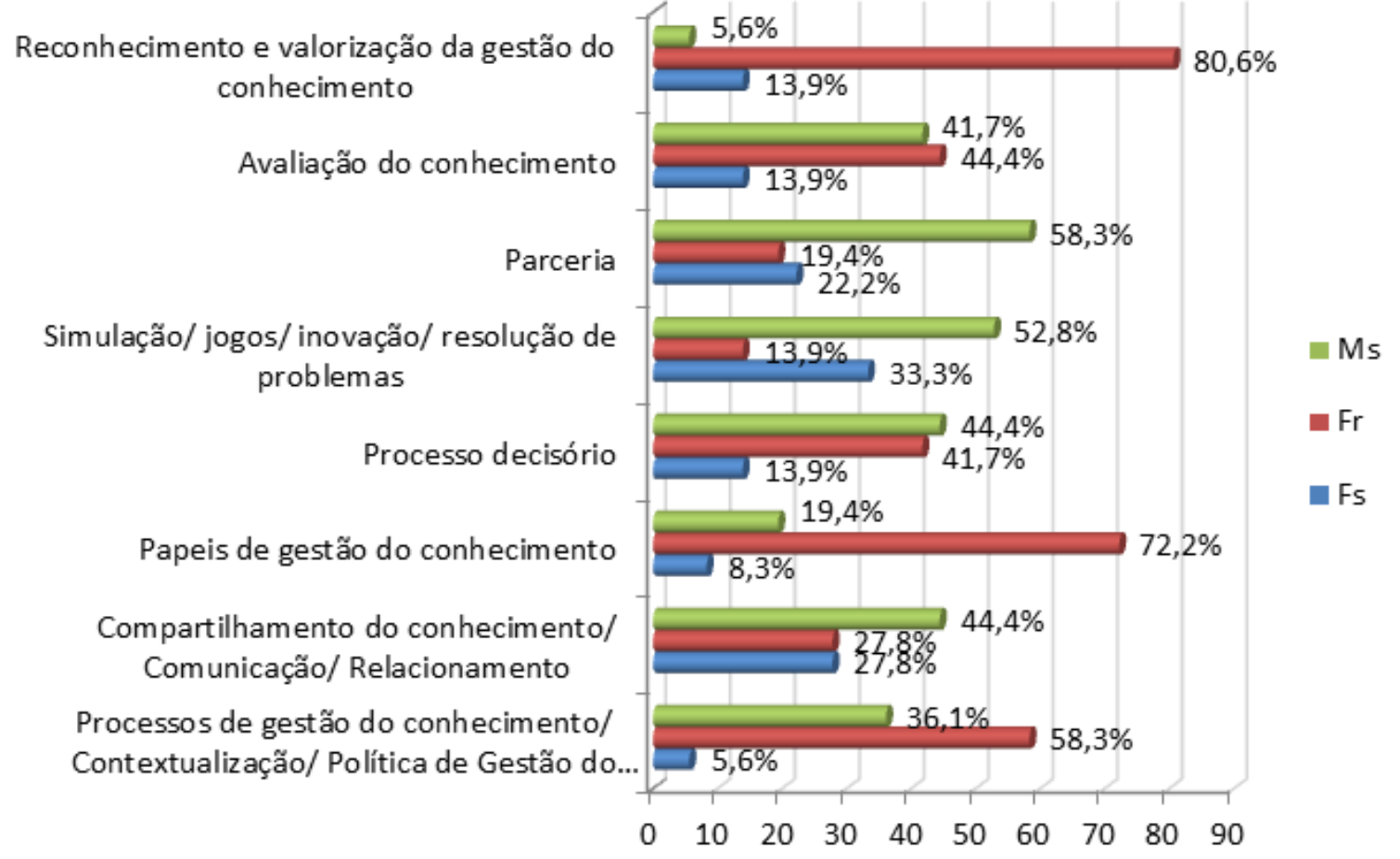

GRÁFICO 1: Indicadores de gestão do conhecimento da Seção Descarte.

Fonte: dados da pesquisa 
Quanto ao indicador "Compartilhamento do conhecimento/ Comunicação/ Relacionamento" percebeu-se como "moderado", significa que moderadamente a organização tenta entender o impacto dos relacionamentos na produtividade antes de automatizar as tarefas e substituir o contato pessoa-a-pessoa pelo contato pessoa-computador. Além disso, moderadamente quando descarta um negócio ou grupo / equipe de pessoas, trata-os com dignidade e respeito, apesar de não imaginar como perseguir atividades de valor mais alto em vez de dispensá-las, como revelou o indicador anterior. E, na organização, moderadamente faz-se uso de relacionamentos informais com negócios relacionados à sua área, para manter a base de conhecimento atualizada.

A análise do indicador "Papéis de Gestão do Conhecimento", demonstrou que de forma "fraca" a organização participa de grupos formais de pesquisa sobre seu ramo de negócio para ajudar a decidir se necessitam adquirir conhecimentos novos; apesar de manterem moderadamente relacionamentos informais com negócios relacionados à sua área para manter a base de conhecimento atualizada, como revelou o indicador "Compartilhamento do conhecimento/ Comunicação/ Relacionamento".

O indicador "Processo decisório", revelou que "moderadamente", na organização, a decisão de adquirir conhecimento é baseada em quanto se pode alavancá-lo e, as decisões de descarte de conhecimento são baseadas na importância estratégica do capital intelectual e nas projeções financeiras, apesar de na organização o descarte ocorrer de forma inconsciente e sem saber dos componentes de conhecimento que eles contêm, conforme o indicador "Processos de Gestão do Conhecimento/ Contextualização/ Política de Gestão do conhecimento".

Além disso, moderadamente a organização recusa trabalhar para um cliente / beneficiário / parceiro se tal trabalho não constrói conhecimento útil; e, terceiriza habilidades que não sustentam sua competência essencial, como uma forma de gastar energia naquilo estrategicamente importante.

Quanto ao indicador "Simulação/ jogos/ inovação/ resolução de problemas", revelou que, "moderadamente" a organização prefere utilizar os recursos e as habilidades construídos localmente para testar ou viabilizar novas idéias de negócio. Porém, a partir dos indicadores anteriores percebeu-se que a organização pode ter dificuldade na operacionalização desse indicador, já que: descarta o conhecimento construído localmente sem saber seu conteúdo, não rever suas práticas de gestão de pessoas para incentivar e evitar desligamento de servidores que podem ser estrategicamente importantes, não participa de grupos de estudo para atualizar o conhecimento de seus repositórios, nem reinstrumenta suas habilidades para decidir sobre aceitar novos trabalhos. Portanto, os recursos locais de testar ou viabilizar novas idéias estão comprometidos, causando abstenção de inovação na organização.

Em relação ao indicador "Parcerias", percebeu-se que a instituição pesquisada utiliza de forma "moderada" das parcerias para produzir aprendizagem, pois as pessoas moderadamente participam de comunidades em rede, moderadamente são colocadas em outras organizações como aprendizes para compartilhar tecnologias da informação, ideias para levar produtos inovadores, conhecimentos ou habilidades. Sendo assim, a instituição pode apresentar alguma dificuldade em manter a base de conhecimento atualizada.

Quanto ao indicador "Avaliação do Conhecimento", verificou-se que, de forma "fraca" na organização se pensa / reflete se o conhecimento já adquirido pode ser usado de outras maneiras 
antes de aceitar novos trabalhos (projetos ou serviços novos), e rotineiramente, não se examina se o conhecimento que é sustentado na organização poderá mantê-la viável no futuro.

O indicador "Reconhecimento e valorização da Gestão do Conhecimento" teve a intensidade mais "fraca", corrobora com os resultados da maioria dos demais indicadores analisados até aqui, e significa que regularmente a organização não rever suas práticas de valorização de pessoal para se certificar que não está perdendo pessoas com conhecimento estrategicamente importante e, que na organização não se leva em conta o impacto que tem o fato de deixar ir embora pessoas com capacidade de contribuição, lealdade e compromisso. Esse resultado é percebido por $80,6 \%$ dos gestores respondentes da pesquisa, conforme a Tabela 2 , entre eles, $100 \%$ dos gestores com função de Assessoria.

TABELA 2: Distribuição da população quanto a Reconhecimento e valorização da gestão do conhecimento por função que ocupa

\begin{tabular}{c|c|c|c|c|c|c|c|c}
\hline $\begin{array}{c}\text { Função que } \\
\text { ocupa/ocupou }\end{array}$ & $\mathrm{Fs}$ & $\%$ & $\mathrm{Fr}$ & $\%$ & $\mathrm{Ms}$ & $\%$ & Total & $\%$ \\
\hline Assessoria & 0 & $0,0 \%$ & 6 & $100,0 \%$ & 0 & $0,0 \%$ & 6 & $100 \%$ \\
\hline Chefia & 2 & $22,2 \%$ & 7 & $77,8 \%$ & 0 & $0,0 \%$ & 9 & $100 \%$ \\
\hline Coordenação & 1 & $25,0 \%$ & 3 & $75,0 \%$ & 0 & $0,0 \%$ & 4 & $100 \%$ \\
\hline Direção & 1 & $33,3 \%$ & 1 & $33,3 \%$ & 1 & $33,3 \%$ & 3 & $100 \%$ \\
\hline Gerência & 1 & $7,1 \%$ & 12 & $85,7 \%$ & 1 & $7,1 \%$ & 14 & $100 \%$ \\
\hline Total & 5 & $13,9 \%$ & 29 & $80,6 \%$ & 2 & $5,6 \%$ & 36 & $100 \%$
\end{tabular}

Fonte: dados da pesquisa

Portanto, verifica-se que na organização pesquisada o conhecimento é descartado de forma inconsciente quando: a organização não busca rever suas práticas de valorização de pessoal, pois não leva em conta o impacto de deixar ir embora servidores com capacidade de contribuição, lealdade e compromisso, experts com conhecimento estratégico essencial do negócio com capacidade de filtrar o conhecimento; não reflete sobre se o conhecimento construído pode ser utilizado de outras maneiras antes de descartá-lo; não tem consciência dos componentes que contém o conhecimento descartado; a organização não incentiva a participação dos servidores em grupos de discussão sobre seu ramo de negócio etc. Portanto, podem estar deixando de adquirir conhecimento estratégico que agregue valor à sua competência essencial, ou de descobrir caminhos de sucesso trilhados pela organização que produziram bons resultados, inibindo-se a inovação.

Contudo, a instituição utiliza moderadamente de alianças / parcerias com outras organizações para determinar a necessidade de aquisição de novos conhecimentos, apesar das pessoas não participarem de comunidades em rede, nem são colocadas em outras organizações como aprendizes para compartilhar tecnologias da informação, idéias para levar produtos inovadores, conhecimento ou habilidades.

\section{CONCLUSÃO}

Considerando-se a análise dos dados e indicadores estudados, à luz da revisão teórica e, a partir do objetivo proposto, percebeu-se que a instituição não dispõe de aspectos estratégicos 
(decisão de gerir o conhecimento), operacionais formais (de transformar o conhecimento tácito em explícito, realizar análises e decidir pelo descarte ou não) e humanos de descarte do conhecimento, pois não busca significados importantes nas novas atividades a serem realizadas, de forma que as pessoas sintam que estão ganhando com a mudança.

Portanto, na organização pesquisada o descarte do conhecimento não ocorre ou ocorre de forma inconsciente, pois se percebeu através dos resultados que: a organização não reflete sobre o conhecimento que construiu se pode ser utilizado de outras maneiras antes de descartá-lo; os gestores, não tem consciência dos componentes que contém o conhecimento descartado; a organização não percebe que está perdendo pessoas com conhecimento estrategicamente importante; a instituição não tenta perseguir atividades de valor mais alto ou alocar as pessoas nas habilidades e expertises certas antes de pensar em dispensá-las, e não tem a capacidade de se reinstrumentar antes de empregar novas habilidades com um novo grupo de trabalhadores do conhecimento.

Também não estabelece mecanismos, como redes de pessoas ou grupos de pesquisa sobre o ramo de negócio da instituição, para ajudar a decidir a necessidade de aquisição do conhecimento; pouco reflete sobre recusar trabalhos se não construir conhecimento que agregue à instituição e sobre terceirizar habilidades que não sustentam a competência essencial da instituição; e, utiliza pouco das parcerias para produzir aprendizagem.

Conclui-se ainda que: a instituição pesquisada não examina as suas bases de conhecimento com frequência para descartar o conhecimento que não traz mais valor impedindo a renovação / inovação, bem como, não dispõe de práticas de gerenciamento da enxurrada de informações disponíveis no mercado para converter as mais relevantes em fontes de valor e inovação.

Além disso, os resultados da pesquisa ratificam que a investigação científica sobre Gestão do Conhecimento no Brasil ainda tem se concentrado nos processos táticos de criação de conhecimento, uso e transferência; dedicando-se pouca atenção aos estudo de descarte, e isso tem causado um crescimento científico heterogêneo sobre a temática.

Por outro lado, apesar da maioria dos gestores respondentes da pesquisa terem afirmado já ter ouvido falar em Gestão do Conhecimento e dizer que conheciam práticas de GC na instituição, percebeu-se que a preocupação da organização ainda está apenas em adquirir conhecimento, mesmo que este não esteja diretamente alinhado à estratégia organizacional, e manter a base do conhecimento intacta e atualizada; mesmo não se esforçando para evitar que as pessoas, que filtram, direcionam e atualizam as informações permaneçam na instituição, nem viabiliza tecnologias da informação e idéias para produzir produtos inovadores a partir do conhecimento que consegue adquirir.

Os resultados sinalizam contradições, pois a organização que precisa disseminar saberes de ponta para produtores rurais, não consegue descartar conscientemente o conhecimento datado que possui e que não agrega mais valor. Portanto, a organização não está preparada para usufruir dos benefícios do descarte do conhecimento como uma prática que pode gerar a inovação na sua área de conhecimento, e está enxergando esse novo modelo de gestão com as lentes do passado.

\section{REFERÊNCIAS BIBLIOGRÁFICAS}

1. ACEVEDO, C. R.; NOHARA, J. J. Monografia no curso de administração: guia completo de 
conteúdo e forma. 2. ed. São Paulo: Atlas, 2006.

2. BATISTA, Fábio F. Modelo de gestão do conhecimento para a administração pública brasileira: como implementar a gestão do conhecimento para produzir resultados em benefício do cidadão. Brasília: IPEA, 2012.

3. BARRETO, Aldo de Albuquerque. Memórias, esquecimento e estoque de informação. 2007. Disponível em: http://www.aldoibct.bighost.com.br/MemorEsquecim.pdf. Acessado em: 12 de julho de 2012.

4. BASSETTO, Benedita J. REVISTA ELETRÔNICA ADMINISTRAÇÃO: GESTÃO \& TECNOLOGIAS: Vol. 1, № 1, p. 1-17. São Paulo: Faculdade Marechal Rondon, 2011.

5. BRITO, Lydia M. P; OlIVEIRA, Patrícia W. S. de; CASTRO, Ahiram B. C. de. REVISTA DE ADMINISTRAÇÃO PÚBLICA: Vol. 46, № 5, p. 1341-1366. Rio de Janeiro: Fundação Getúlio Vargas, 2012.

6. BUKOWITZ, Wendi R.; WILLIAMS, Ruth L. Manual de gestão do conhecimento: ferramentas e técnicas que criam valor para a empresa. São Paulo: Bookman, 2002.

7. CAPORAL, Francisco Roberto. A redescoberta da Assistência Técnica e Extensão Rural e a implementação da Pnater: nova âncora para a viabilização de acesso a políticas de fortalecimento da Agricultura Familiar. 2009. Disponível em: http://www.pronaf.gov.br/dater/arquivos/0730620568.pdf. Acesso em: 27 de novembro de 2012.

8. COSTA, Ivani; VASCONCELOS, Ana C. F. de; CANDIDO, G. A. Diagnóstico de gestão do conhecimento como mecanismo para criação de valor: um estudo exploratório no SEBRAE-PB. Revista Gestão Industrial, Paraná, v. 5, n. 2: UTFPR, 2009. Disponível em: <http://www.pg.cefetpr.br/depog/periodicos/index.php/revistagi/article/viewArticle/346>. Acesso em: 09 de jul. de 2010.

9. CHOO, Chun W. A. Organização do conhecimento: como as organizações usam a informação para criar significado, construir conhecimento e tomar decisões. São Paulo: Senac, 2003.

10. DAVENPORT, Thomas; PRUSAK, Laurence. Conhecimento empresarial: como as organizações gerenciam o seu capital intelectual. Rio de Janeiro: Elsevier, 1998.

11. DIHL, Winicyus; HOLANDA, Lucyanno M. C. de; FRANCISCO, Antonio C. de. A utilização do método de diagnóstico para a gestão do conhecimento: estudo de caso numa empresa incubada (ALFA). Revista eletrônica FAFIT/FACIC, v.1, n.1, jan./jun. São Paulo: FAFIT/FACIC, 2010.

12. DRUCKER, Peter F. Sociedade Pós-capitalista. São Paulo: Pioneira, 1993.

13. EMATER. Relatório de Gestão de Pessoas. Natal: Ungraf, 2009.

14. FERNANDEZ, V.; SUNE, A. Organizational Forgetting and its causes: an empirical research. Journal of Organizational Change Management, Vol.22, No.6, pp. 620-634, 2009. Disponível em

$<$ http://upcommons.upc.edu/eprints/bitstream/2117/6230/1/organizational\%20forgetting.pdf>. Acesso em: 02/12/2013.

15. GIL, A. Carlos. Método e técnicas de pesquisa social. 5. ed. São Paulo: Atlas, 2006.

16. HOLANDA, Aurélio B. de H. Minidicionário Aurélio da língua portuguesa. 8a ed. Curitiba: Positivo, 2010. 
17. HOU, Huel Tse. New Research on Knowledge Management Applications and Lesson Learned. Croatia: InTech, 2012.

18. IGARASHI, Wagner; IGARASHI, Deisy C. C.; VIEIRA, Eleonora M. F.; TODESCO, José L. Investigação no contexto brasileiro sobre gestão do conhecimento/aprendizagem/tecnologia de informação: pesquisa realizada na Scientific Eletronic Library Online. Cadernos EBAPE.BR, v. 6 , no 2, Jun. 2008.

19. LARA, Consuelo R. D. de. A atual gestão do conhecimento: a importância de avaliar e identificar o capital intelectual nas organizações. São Paulo: Nobre, 2004.

20. MARCONI, Marina de A.; Lakatos, Eva M. Fundamentos de Metodologia Científica. São Paulo: Atlas, 6a Ed., 2008.

21. NONAKA, Ikujiro; TAKEUCHI, Hirotaka. Criação de conhecimento na empresa: como as empresas japonesas geram a dinâmica da inovação. Rio de Janeiro: Campus, 1997.

22. REMOR, Lourdes de C.; MIRANDA, Angélica C.D.; SANTOS, Neri dos.; STEIL, andréia V.; MONGUILHOTT REMOR, Carlos A. Esquecimento Organizacional e suas consequências no processo de aprendizagem organizacional. Revista de Administração Pública. Rio de Janeiro, Maio/jun, 2010. Disponível em: http://www.scielo.br/pdf/rap/v44n3/06.pdf. Acessado em: 01 de outubro de 2012.

23. SILVA, Ricardo J. A.; SICSÚ, A. B; CRISÓSTOMO, A. P. Identificação de processos de conhecimento - estudo multicaso em APL de calçados de Campina Grande. Revista Gestão Industrial. Paraná: $2009 . \quad$ UTFPR, Disponível em: <http://revistas.utfpr.edu.br/pg/index.php/revistagi/article/viewFile/483/366>. Acesso em: 09 de jul. de 2010.

24. SILVA FILHO, M. Marques da. A Extensão Rural em Meio Século: A Experiência do Rio Grande do Norte. EMATER-RN, 2005.

25. SOUZA, W. J.; MARTINS, S. P.; FREITAS, H. M.; AMORIM, M. V.; CRUZ, M. K.; CUNHA, A. S. R. Nova Gestão Pública, nova extensão rural: experiências inovadoras da EMATER-RN. Natal: EDUFRN, 2009.

26. STEWART, Thomas A. Capital intelectual: a nova vantagem competitiva das empresas. Rio de Janeiro: Campus, 1998.

27. SVEIBY, Karl Erik. A nova riqueza das organizações, gerenciando e avaliando patrimônios de Conhecimento. Rio de Janeiro: Campus, 1998.

28. TAKAHASHI, Adrina R. W.; FISCHER, André L. Debates passados, presentes e futuros da aprendizagem organizacional- um estudo comparativo entre a produção acadêmica nacional e internacional. REVISTA DE ADMINISTRAÇÃO MACKENZIE, vol. 10, n. 5. São Paulo/SP, 2009. Disponível em: <http://abadan.libertar.org/tmp1/ojs2.2.2/index.php/RAM/article/viewArticle/288>. Acessado em: 1을 de julho de 2013.

29. TAVARES, Wolmer R. Gestão do conhecimento: Educação e Sociedade do Conhecimento. São Paulo: Ícone, 2010.

30. TERRA, José C. C. Gestão do conhecimento: o grande desafio empresarial. Rio de Janeiro: Elsevier, 2005.

31. TRIGUEIRO, Francisco M. C.; MARQUES, Neiva de A. Teoria da Administração I. Florianópolis: UFSC, 2012. 
32. VERGARA, S. C. Projetos e relatórios de pesquisa em administração. 11. ed. São Paulo: Atlas, 2007.

33. WANG, Sheng; NOE, Raymond A. Knowledge Sharing: A review and diretions for future research. Human Resource Management Review. Vol. 20, pp. 115-131, 2010. Disponível em $<$ http://www.ucdenver.edu/academics/colleges/CLAS/Centers/writing/Documents/HR_Man agament.pdf>. Acesso em: 04/03/2014.

34. WOSZEZENKI, Cristiane R.; BESEN, Fabiana; SANTOS, Jane L.; STEIL, Andrea. Mapeamento das Publicações Acadêmico-Científicas sobre Desaprendizagem Organizacional. Anais do 230 Simpósio Brasileiro de Informática na Educação (SBIE), Rio de Janeiro, 2012. Disponível em: < http://www.lbd.dcc.ufmg.br/colecoes/sbie/2012/0038.pdf>. Acessado em: 10 de julho de 2013.

35. YIN, Robert K. Estudo de Caso: Planejamento e Métodos. 4ạ. Ed. Porto Alegre: Bookman, 2010. 